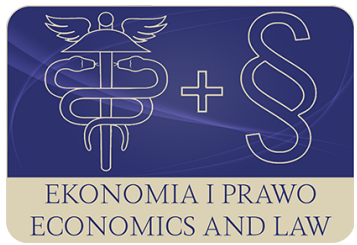

EKONOMIA I PRAWO. ECONOMICS AND LAW

Volume 20, Issue 2, June 2021

p-ISSN 1898-2255, e-ISSN 2392-1625

www.economicsandlaw.pl

EKONOMIA I PRAWO
ECONOMICS AND LAW

ORIGINAL ARTICLE

received 30.04.2021; revised 20.06.2021; accepted 30.06.2021

Citation: Matuszewski, M. (2021). Synergies in mergers and acquisitions in the copper mining industry. Ekonomia i Prawo. Economics and Law, 20(2), 277-286. https://doi.org/10.12775/EiP.2021.016.

\title{
Synergies in mergers and acquisitions in the copper mining industry
}

\author{
MACIEJ MATUSZEWSKI \\ University of Economy in Wroclaw, the Doctorate School, Poland \\ KGHM Polska Miedź ul. M. Curie-Skłodowskiej 48, 59-301 Lubin, Poland \\ $\square$ maciej.matuszewski@ue.wroc.pl \\ (iD) orcid.org/0000-0001-9985-3983
}

\begin{abstract}
Motivation: The results of the research shall broaden the knowledge required for interpretation of synergy effects in the mineral mining sectors. The results obtained shall be used for further research when developing procedures for analysis and evaluation of the effects of mergers and acquisitions in the copper ore mining sector and may also be used by the management of an acquiring party involved in mergers and acquisitions in the copper mining sector.

Aim: The aim of the research, the results of which has been presented in this article, was to identify areas of processes concerning operations and costs as possible sources of synergies in the merger and acquisition processes in the copper ore mining sector. A critical review of literature about the subject as well as desk research have been used to make the study.

Results: The obtained results confirm the need for synergy effects, in the areas of both operations and costs, to be considered in the processes of mergers and acquisitions in the copper ore mining sector. Taking into account the strategy map and the cost structure in the copper mining sector, we may conclude that the costs of mining and milling are the key parameters of the cost structure (in relation to overheads) and they should be considered as the specific subject of due diligence, because apparently, this is the area where the greatest synergy value may be achieved.
\end{abstract}

Keywords: synergies; mergers and acquisitions; M\&A; copper industry sector JEL: G340; L100; L210; L250; L610 


\section{Introduction}

Synergy is a key motive behind mergers and acquisitions. Despite the popularity of synergies in scientific studies and business practice, it is difficult to quantify them, manage implementation, let alone finding performance indicators, and all of this also applies to the copper ore mining sector. Moreover, overestimation of synergies may lead to an excessively high purchase price and thus affect the effectiveness of mergers and acquisitions. Taking into account the strategy map and the cost structure in the copper mining sector, we may conclude that the costs of mining and milling are the key parameters of the cost structure (in relation to overheads) and they should be considered as the specific subject of due diligence, because apparently, this is the area where the greatest synergy value may be achieved.

Synergies are among the most significant motives to inspire mergers and acquisitions. They are present both in theoretical studies concerning the area of mergers and acquisitions (M\&A) and in business practice. The management members, when explaining their reasons for a takeover or merger, often refer to synergy aspects, indicating the possible benefits that can be achieved after the transaction is completed.

The aim of the article is to present the specifics of the synergy analysis, with particular reference to the copper mining sector. The article was prepared based on exploration of the literature on the subject and analysis of the reports on the copper ore mining sector.

\section{Literature review}

When considering the concept of synergy, the classic expression $2+2=5$ often comes to our mind. Despite the common intuitive knowledge about synergies, it is not easy to define them, let alone quantifying them, managing implementation or finding performance indicators.

The word synergy comes from the Greek word "synergos", meaning working together. In general, the most common definition of synergy in business is the ability to generate additional value by two or more companies creating a joint operation, that would not be possible in case of separate operations. According to the classification proposed by Goold \& Cambell (1998), we can distinguish six forms that synergies can take (Table 1 ).

Synergies are also to create additional cash flows. If the company could have generated the assumed cash flows on its own, as a rule, they would not be a synergy effect.

In the literature on the subject, one can find many classifications of synergies based on areas of realisation and effects of implementation thereof. A simplified classification assumes two categories of synergies: the revenue synergies (increasing the level of revenues) and the cost synergies including reducing the level of costs (Early, 2004). Cost synergies assume improved use of re- 
sources and competences (in case of enterprises failing to use $100 \%$ of them or to work effectively in the current configuration). After M\&A transactions, the combined resources or operations boosted by a new or related activity shall enable reduction of unit costs (Scholes et al., 2002). On the other hand, Lubatkin (1983) has identified synergies derived from economy of scale and cost savings due to entity's market position after merger and improved risk assessment. In fact, synergies may involve areas other than those indicated above, they may be independent or interweave within the above groups, which increases the difficulty in measuring and evaluating them.

\subsection{Classifications of synergies}

Hamza et al. (2016) have indicated two main categories of synergies: the operational synergies (related to the operating cycle: growth in revenues and market power, fewer investments) and the financial synergies - risk reduction due to diversification, tax savings, reduced risk of insolvency. The classification based on financial and operational areas of synergies is the most frequent division thereof in the literature on the subject.

Financial synergies, according to the assumptions presented by Damodaran (2005), may prompt an increase in a company's cash flow, a decrease in its cost of capital or both of the effects simultaneously. The reduced cost of capital to be borne by the acquiring party (or a new entity created as a result of the completed merger) translates into greater opportunities for generating added value from projects to be implemented (the increased spread between the rate of return on investment and the value of the cost of capital), which results in increased value for shareholders (Lewellen, 1971). This translates into an increase in the company's credit-worthiness and increases their chances of acquiring loans in the future (Saxena, 2012). This is due to the assumed stabilization of generated cash flows. Additionally, in the event of an increase in the profit growth rate, it should translate into an increase in the price / earnings ratio $(\mathrm{P} / \mathrm{E})$ and thus increase the capitalization of the company. Value in terms of financial synergies can also be generated through tax savings (e.g., purchase of a company generating tax losses may be used by a profit-generating entity to reduce the level of effective taxation).

On the other hand, the operational synergies are represented by the opportunity of obtaining the effect of:

- economy of scale which is the effect of lowering unit costs by increasing the number of manufactured products - increase in revenues (Houston et al., 2001);

- economy of scope which enables certain resources and skills (e.g., in sales and marketing) to be used for other products (DeLong, 2003).

Operational synergies shall contribute to increase in production, the accelerated growth of an organization as well as better resource utilisation. 
A summary of synergies constituting motives in M\&A strategies, as broken down by operational and financial type thereof, has been presented in Table 2.

Both financial and operational synergies are aimed at improving the efficiency of the company's operations. Garzella \& Fiorentino (2014) argue that $75.76 \%$ of the benefits derived from mergers and acquisitions are related to the areas of operational and financial synergies.

\subsection{Synergy as seen from perspectives of both the acquiring and the acquired parties to business takeovers}

Synergy is a concept frequently mentioned in connection with mergers and acquisitions. Based on the general definition of synergy, the definition of synergy with reference to M\&A transactions may be standardized by saying that synergies constitute the present value of the additional cash flow generated due to the acquisition or merger of two companies, which neither company would not be able to generate on its own.

The word synergy is one of the most overused words in the business world, when trying to justify the most problematic mergers and acquisitions. Too optimistic estimation of synergy effects is often an explanation for negative results of M\&A transactions, and the synergies themselves are in many cases the main motives behind unsuccessful transactions (Harding \& Rovit, 2004). Synergy effects are estimated on the basis of internal assumptions, prior to the transaction, and the valuation process may be one of the most ambiguous aspects of analysis thereof. Research on synergy effects does not give unequivocal results about reality or feasibility thereof, moreover, some researchers believe that drawing conclusions about the reality and amount of synergies may be difficult or even impossible on the basis of the analyses available (Hietala et al., 2002).

From the perspective of the acquiring party, synergies constitute a significant form of incentives to conclude a transaction, and their quantification may additionally affect the valuation of an asset and thus the purchase price. On the other hand, the selling party may focus on potential synergies for the potential acquirer, adequately highlighting the opportunities for generating added value through realisation thereof. For the seller, it may be an important aspect of communication in connection with the so-called "exit story". On the part of the acquirer the estimated synergies are the reason why they are willing to increase the purchase price for the acquired company or asset. Even if some synergies may be generated in the future, if overvalued they translate into an excessively high purchase price, commonly known as the "winner curse" (Roll, 1986). Its other name is hubris theory which means overestimation of the opportunity to gain synergy, leading to an exaggerated evaluation of the asset to be acquired. The psychological aspect and motivation of the top management are also significant. Exaggerated confidence is another aspect making the acquiring party to overpay in acquisition processes (Billett \& Qian, 2004). The bidder to buy an asset shall be, in principle, the one whose bid is the highest. The higher 
the proposed price for the takeover, the greater are the synergies as estimated before concluding the transaction, which will have to be realized in the period after the transaction, in order to generate adequate value for shareholders.

Synergies are particularly significant from the perspective of the acquirer who has significantly less information available than the seller. Information asymmetry acting to the disadvantage of the acquirer translates into the need to build an appropriate strategy for obtaining information by the acquirer in order to properly analyse potential synergies. Mergers and acquisitions, from the acquiring party's perspective, require appropriate internal resources (employees), external resources (e.g., advisers, investment banks, lawyers), which, often due to the time constraint, shall involve appropriate actions focused on key aspects of a given transaction. This is also relevant to focusing the due diligence actions, in particular on areas that may constitute a key information resource, also for analysis of potential synergies.

\section{Methods}

In a study by Cullinan et al. (2004), two-thirds of managers admitted that they had over-estimated synergies. Due to the imperfection of the synergy estimation process, companies consciously resign (by means of internal regulations) from taking into account the value of synergies when estimating the value of the acquired company. The strict exclusion of all synergies in the valuation process also seems unjustified, so a possible solution, as suggested by Cullinan et al. (2004), is a detailed due diligence process to ensure a reasonable assessment of future benefits, considering possible risks associated with making them real.

Cullinan et al. (2004) have suggested using the due diligence process to differentiate and assess the feasibility of synergies. This analysis should also include the possible time frame for synergy realization. As a solution to this issue, the authors proposed a synergy map where potential synergies are best identified as a series of concentric circles (Scheme 1). The synergy map may also serve as a remedy to information asymmetry in mergers and acquisitions, allowing the acquirer to focus on the most significant aspects of potential synergies, i.e. on the target value of the transaction.

Areas that are close to the center constitute most often the cost synergies that can be realized quickly and prove successful. The first area covers duplicate functions in the combined units, including primarily administrative and corporate functions. At the same time, it is also the part that is easiest to implement and carry out. In the next area, the part covering joint operating activities has been specified. External synergies involve revenue generating areas that require a lot of time and management and are less likely to be implemented. According to the authors, the indicated categorization of synergies greatly facilitates subsequent valuation thereof. When determining the exit price, the discount factor for synergies should increase as you move away from the centre. The structure of the strategy map also indicates a greater significance of the cost synergies 
(located closer to the central circle) as compared to the revenue synergies. With reference to the division into the operational and financial synergies, it can be concluded that the synergy map underlines the significance of the operational synergies versus the financial ones, specifically the economy of scale (focused on cost issues) versus the economy of scope (assuming its reference to revenue issues).

\section{Results}

According to the analyses curried out by S\&P Global Intelligence, in 2020, the average value of takeover transactions within the base metals sector (which copper belongs to), amounted to USD 274 million (Wright, 2021). The sheer value of M\&A transactions shows the significant role they play in the activities of entities within the sector. The total value and number of transactions in the base metals sector has been presented in Chart 1 .

Research into mergers and acquisitions shows that they often fail. An inherent element preceding mergers and acquisitions is the due diligence procedure, which includes the analysis of an asset to be the subject of the future transaction. Taking into account the synergy maps, the key areas to create a value should be looked for specifically in the cost area. However, in the literature and available market studies, there are no detailed studies taking into account the cost structure in the copper mining sector. The studies vary in the type of mines (underground and open-pit), geographic location and the type of mining method (flotation and SX-EW).

Cochilco (Comisión Chilena del Cobre - Chilean Ministry of Mining), in their summaries have analysed the mining costs of the largest mines operating in Chile. The institution has analysed 21 of the largest mines in operation in Chile. The analysis has covered only mines located in one geographical location and, due to the specific mining conditions in Chile, all of them are the open-pit mines, nevertheless, the mines account for $92 \%$ of production in Chile and $25 \%$ of the world production. As the most significant cost components, Cochilco has indicated services ( $29 \%$ of total costs), depreciation ( $28 \%$ of costs), consumables (17\%), personnel costs (12\% of costs) and energy ( $8 \%$ of costs). The depreciation posted in books excluded, services and consumables constitute the most significant cost components and equal $46 \%$ of costs. On the other hand, on the basis of the analysis of 63 mines, Curry et al. (2014) have indicated that the average costs of mining and processing did not differ significantly between the mines and had a similar share in the total operating costs of enterprises. The significance of the type of mines and minerals has been noted, as the costs of milling in underground mines were much lower than the corresponding costs in openpit mines, and in gold mines they constituted much greater share in the operating costs than in copper mines. The correlation between costs of mining, costs of milling and general administrative costs in total operating costs has been noted to vary between 43:43:14 and 45:45:10. 
Finally, based on the research by Curry et al. (2014), we may conclude that mining and milling costs are the key operating costs in the copper mining sector.

\section{Conclusion}

Synergies, despite ambiguities in definition and analysis thereof, are among the most important aspects of mergers and acquisitions. This is a significant issue also in the copper mining sector, where M\&A transactions provide opportunities for building value for shareholders. Analysis of the theoretical map of synergies reveals the key aspect of duplicated functions, as the area with the highest probability of implementation in a relatively short period of time, then go in turn joint operational activity, use of infrastructure and revenue synergies (Scheme 2).

In the context of the copper mining sector and the significance of cost synergies, the cost structure in the mining industry considered, we may conclude that mining and milling costs are the key parameters of the cost structure (in relation to overheads) and they should be considered as the specific subject of due diligence, because apparently, this is the area where the greatest synergy value may be achieved.

\section{References}

Billett, M.T., \& Qian, Y. (2004). Are overconfident managers born or made: evidence of self-attribution bias from frequent acquirers. Management Science, 54(6), 1037-1051. https://doi.org/10.2139/ssrn.687534.

Cullinan, G., Le Roux, J.M., \& Weddigen, R.M. (2004). When to walk away from a deal. Harvard Business Review, 82(4), 96-105.

Curry, J.A., Ismay, M.J., \& Jameson, G.J. (2014). Mine operating costs and the potential impacts of energy and grinding. Minerals Engineering, 56, 70-80. https://doi.org/10.1016/j.mineng.2013.10.020.

Damodaran, A. (2005). The value of synergy. https://doi.org/10.2139/ ssrn. 841486 .

DeLong, G. (2003). Does long-term performance of mergers match market expectations: evidence from the US banking industry. Financial Management, 32(5), 5-25. https://doi.org/10.2307/3666334.

DePamphilis, D. (2019). Mergers, acquisitions, and other restructuring activities: an integrated approach to process, tools, cases, and solutions. Elsevier. https://doi. org/10.1016/C2017-0-02823-9.

Early, S. (2004). New McKinsey research challenges conventional M\&A wisdom. Strategy \& Leadership, 32(2), 4-11. https://doi. org/10.1108/10878570410699069.

Garzella, S., \& Fiorentino, R. (2014). A synergy measurement model to support the pre-deal decision making in mergers and acquisitions. Management Decision, 52(6), 1194-1216. https://doi.org/10.1108/MD-10-2013-0516. 
Goold, M., \& Campbell, A. (1998). Desperately seeking synergy. Harvard Business Review, 76(5), 131-143

Hamza, T., Sghaier, A., \& Thraya, M.F. (2016). How do takeovers create synergies: evidence from France. Studies in Business and Economics, 11(1), 54-72. https://doi.org/10.1515/sbe-2016-0005.

Harding, D., \& Rovit, S. (2004). Mastering the merger: four critical decisions that make or break the deal. Harvard Business Review Press.

Hietala, P., Kaplan, S.N., \& Robinson, D.T. (2002). What is the price of hubris: using takeover battles to infer overpayments and synergies. NBER Working Paper Series, 9264, 1-44. https://doi.org/10.3386/w9264.

Houston, J.F., James, C.M., \& Ryngaert, M.D. (2001). Where do merger gains come from: bank mergers from the perspective of insiders and outsiders. Journal of Financial Economics, 60(2-3), 285-331. https://doi.org/10.1016/ S0304-405X(01)00046-0.

Lewellen, W. G. (1971). A pure financial rationale for the conglomerate merger. The Journal of Finance, 26(2), 521-537. https://doi.org/10.2307/2326063.

Lubatkin, M. (1983). Mergers and the performance of the acquiring firm. Academy of Management Review, 8(2), 218-225. https://doi.org/10.5465/ amr.1983.4284724.

Roll, R. (1986). The hubris hypothesis of corporate takeovers. Journal of Business, $59(2), 197-216$.

Saxena, S. (2012). Mergers and acquisitions as a strategic tool to gain competitive advantage by exploiting synergies: a study of merging \& non merging firms in Indian aluminium industry. In S.S. Bhakar, \& V.K Pandey (Eds.), Innovation and adaptability: twin engines of sustained growth (pp. 48-61). Excel Books. https://dx.doi.org/10.2139/ssrn.2086114.

Scholes, K., Johnson, G., \& Whittington, R. (2002). Exploring corporate strategy. Financial Times Prentice Hall.

Wright, N. (2021). Mining M\&A in 2020: deal activity bounces back in H2 after disrupted Hl. Retrieved 14.03.2020 from https://www.spglobal.com/marketintelligence/en/news-insights/research/mining-ma-in-2020-deal-activity-bounces-back-in-h2-after-disrupted-hl.

\section{Acknowledgements}

Author contributions: author has given an approval to the final version of the article.

Funding: this research was fully funded by the KGHM Polska Miedź.

Note: the results of this study were presented at 9th Scientific Conference: Contemporary Economic Problems 'Thirty years of transformation' (September, 16, 2020, online, Poland). 


\section{Appendix}

\section{Table 1.}

\section{Forms and extent of synergies}

\begin{tabular}{ll}
\hline \multicolumn{1}{c}{ Synergy form } & \multicolumn{1}{c}{ Synergy extent } \\
\hline $\begin{array}{l}\text { sharing know-how } \\
\text { coordinating strategies }\end{array}$ & $\begin{array}{l}\text { benefits of sharing knowledge and skills between business units } \\
\text { harmonizing the strategies of business units e.g., to limit competition } \\
\text { in the same markets } \\
\text { sharing tangible assets }\end{array}$ \\
$\begin{array}{l}\text { benefits of sharing assets and resources between business units } \\
\text { coordination of the flow of products and services between business units may } \\
\text { result, for example, in the reduced costs of maintaining inventory or increased } \\
\text { utilisation of production resources }\end{array}$ \\
$\begin{array}{l}\text { increasing the negotiating capacity in the procurement of products and services } \\
\text { increasing negotiating capacity } \\
\text { creating new units }\end{array}$
\end{tabular}

Source: Own preparation based on Goold \& Campbell (1998).

Table 2.

Forms and extent of synergies

\begin{tabular}{|c|c|}
\hline Theoretical concept & Motivation \\
\hline \multirow[b]{2}{*}{ economy of scale and economy of scope } & operational synergies \\
\hline & increasing operational efficiency through economies of scale or scope \\
\hline & financial synergies \\
\hline diversification & lowering a risk or securing a position in a fast-growing market \\
\hline strategic alignment & $\begin{array}{l}\text { acquiring the ability to conform to dynamic changes in the market (e.g., } \\
\text { technology changes, regulatory changes) }\end{array}$ \\
\hline hubris theory & $\begin{array}{l}\text { overestimation of opportunities to achieve synergies leading to an } \\
\text { exaggerated evaluation of the asset to be acquired }\end{array}$ \\
\hline purchase of undervalued assets (q-ratio) & purchase of an asset is cheaper than developing the asset internally \\
\hline wrong management & $\begin{array}{l}\text { an attempt to replace managerial staff that, in the opinion of the acquir- } \\
\text { er, does not work in the best interests of shareholders }\end{array}$ \\
\hline ambitions of managers & $\begin{array}{l}\text { expansion of a company resulting in greater influence as well as higher } \\
\text { salaries of its managerial staff }\end{array}$ \\
\hline tax aspects & taking advantage of the acquired company's tax losses \\
\hline strengthening position in the market & increasing market share \\
\hline over-pricing of the acquiring party & $\begin{array}{l}\text { a high valuation of the acquiring party may encourage them to enter } \\
\text { into m\&a transactions and to pay with their own shares }\end{array}$ \\
\hline
\end{tabular}

Source: Own preparation based on DePamphilis (2019). 
Scheme 1 .

Synergy map

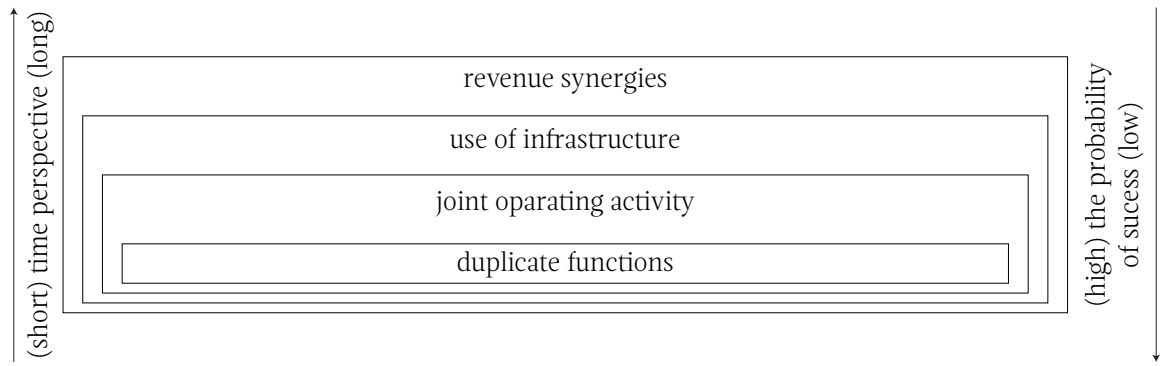

Source: Own preparation based on Cullinan et al. (2004).

Scheme 2.

Summary of the key due diligence areas as part of the synergy analysis to be made by the acquiring party in the copper mining sector

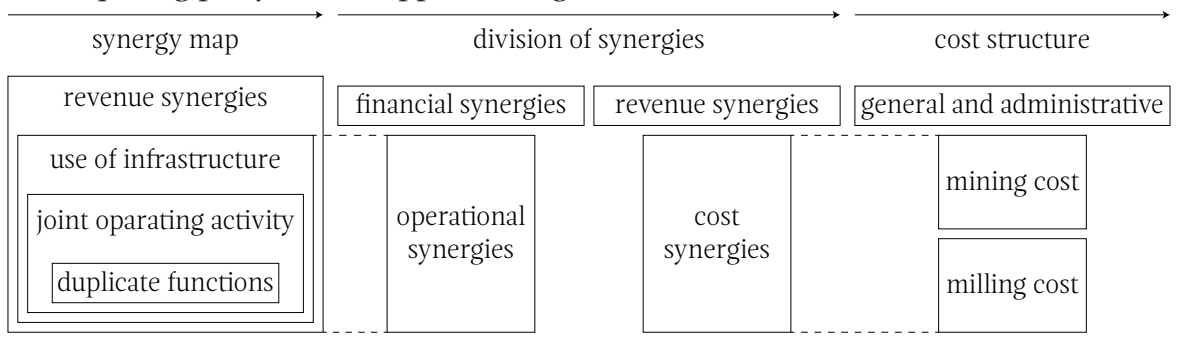

Source: Own preparation based on Cullinan et al. (2004).

Chart 1.

Value (in USD million) and number of M\&A transactions in the base metals sector in 2011-2020

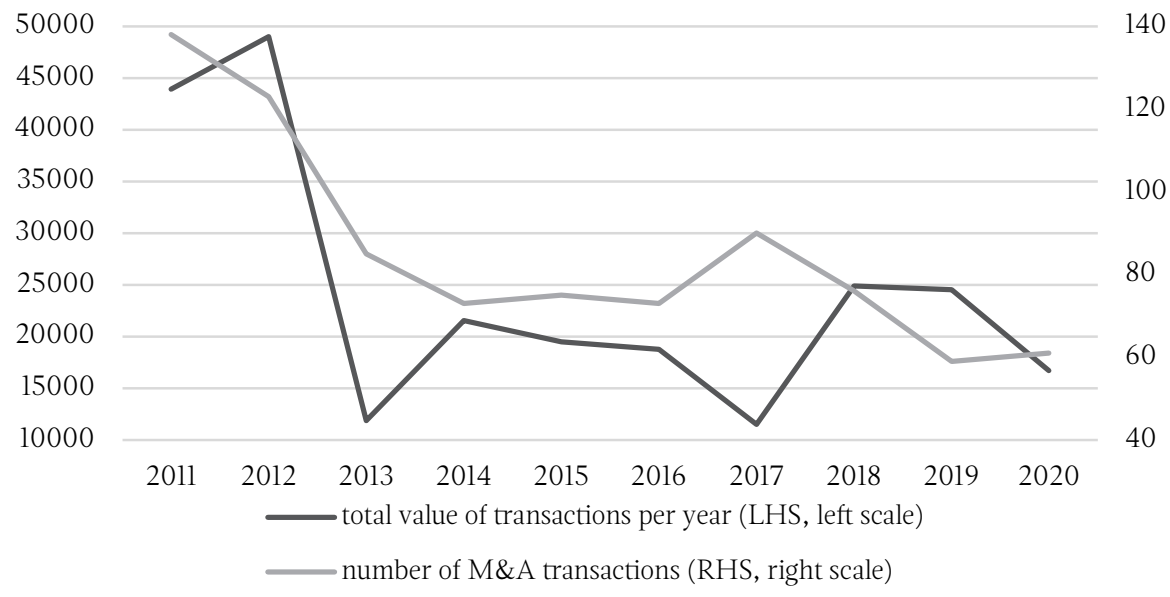

Source: Own preparation based on based on Wright (2021). 